\title{
SEMINÁRIO INTEGRADO, INTERDISCIPLINARIDADE E FORMAÇÃO DOCENTE: TRÍADE NO ENSINO MÉDIO POLITÉCNICO
}

\author{
Everton Bedin. UFRGS Colégio Bom Jesus./Doutor em Educação em Ciências - UFRGS - \\ bedin.everton@gmail.com
}

\begin{abstract}
RESUMO Este artigo tem por intuito apresentar, por meio de uma pesquisa etnográfica de cunho exploratórioqualitativo, via uso da observação e de grupo focal, de que maneira a disciplina Seminário Integrado (SI), advinda com a reestruturação curricular no Etado gaúcho, pode proporcionar, por meio da interdisciplinaridade, subsídios para uma formação docente colaborativa em prol da construção sociocultural e psico-cognitiva do discente. No termino da pesquisa, foi possivel averiguar que os estudantes são instigados a pesquisar e compreender o mundo em que vivem, relacionando teoria e prática para favorecer o próprio desenvolvimento social e cultural. Destarte, percebeu-se que a disciplina tem possibilitado o diálogo de forma colaborativa e interdisciplinar entre os componentes curriculares, seja pela combinação de objetivos ou pela expansão contextualizada dos componentes entre si, uma vez que a elaboração das atividades na disciplina está voltada a estratégias diversas no sentido de fomentar o trabalho em grupo, o diálogo com o outro, a interatividade e a construção de uma docência coletiva. Palavras-chave: Seminário Integrado. Formação colaborativa. Interdisciplinaridade.
\end{abstract}

\section{INTEGRATED SEMINAR, INTERDISCIPLINARITY AND TEACHER TRAINING: TRIAD IN POLYTECHNIC HIGH SCHOOL}

\begin{abstract}
This article is meant to present, through an ethnographic research exploratory and qualitative nature, via use of observation and focus group, how the Integrated Seminar discipline (SI), arising with the curricular restructuring in the gaucho state, can provide, through in the interdisciplinary, aids for collaborative teacher education for the sake of social and cultural construction and psycho-cognitive of the students. At the end of the survey, it was possible to ascertain the students are encouraged to search and understand the world they live in, linking theory and practice to favor their own social and cultural development. Hence, we realize that the discipline has enabled the collaboratively dialogue and interdisciplinary between the curricular components, or by the combination of objectives or contextualized by expansion of components together, once the development of activities in the discipline it is focused on several strategies to foster teamwork, dialogue with the other, interactivity and the construction of a collective teaching.
\end{abstract}

Keywords: Integrated seminar. Collaborative training. Interdisciplinarity.

\section{INTRODUÇÃ̃o}

A Secretaria de Educação do Estado do Rio Grande do Sul, ao nascer do ano de 2011, apresentou uma proposta de ensino para reestruturar o currículo e demudar o Ensino Médio em Ensino Médio Politécnico (EMP), também conhecido como politecnia. Esta proposta vincula-se à realidade social e ao desenvolvimento científico dos estudantes, abrolhando-se sobre a construção autônoma do conhecimento discente e a emersão da interdisciplinaridade 
V,13,n.1: 2017

nos trabalhos docentes. Isto é, a implantação da politecnia na Educação Básica pública do Estado gaúcho exigiu, além de uma reestruturação curricular, avaliação emancipatória, construção do saber por meio da pesquisa e uma adaptação metodológica do professor no viés interdisciplinar.

O documento norteador para a reestruturação curricular ressalta que a "execução desta proposta demanda uma formação interdisciplinar, partindo do conteúdo social, revisitando os conteúdos formais para interferir nas relações sociais e de produção na perspectiva da solidariedade e da valorização da dignidade humana" (SEDUCRS, 2011, p. 4). Ainda, a proposta de politecnia, assegurada nas escolas gaúchas a partir de 2011, vem ao encontro da composição dos Parâmetros Curriculares Nacionais (PCN, 2006, p. 216) a qual visa "um planejamento e desenvolvimento do currículo de forma orgânica, superando a organização por disciplinas estanques e revigorando a integração e articulação dos conhecimentos, num processo permanente de interdisciplinaridade e transdisciplinaridade".

Neste processo, ensinar para a cidadania é uma das principais tarefas dos professores da Educação Básica da rede pública, uma vez que estes se encontram em constante formação e atualização pedagógica, seja pela necessidade e/ou pela segurança em trabalhar com os discentes no viés da pesquisa. Ao tocante, estes professores precisam adotar práticas interdisciplinares dentro de um currículo, readaptado de disciplinas para áreas do conhecimento, que visa à disciplina Seminário Integrado, de formação transversal, conforme imagem a seguir, para superar certas práticas que já não são adequadas e/ou adaptáveis à realidade da sala de aula.

Imagem 1: representação da reestruturação das disciplinas em áreas de conhecimento. 
V,13,n.1: 2017

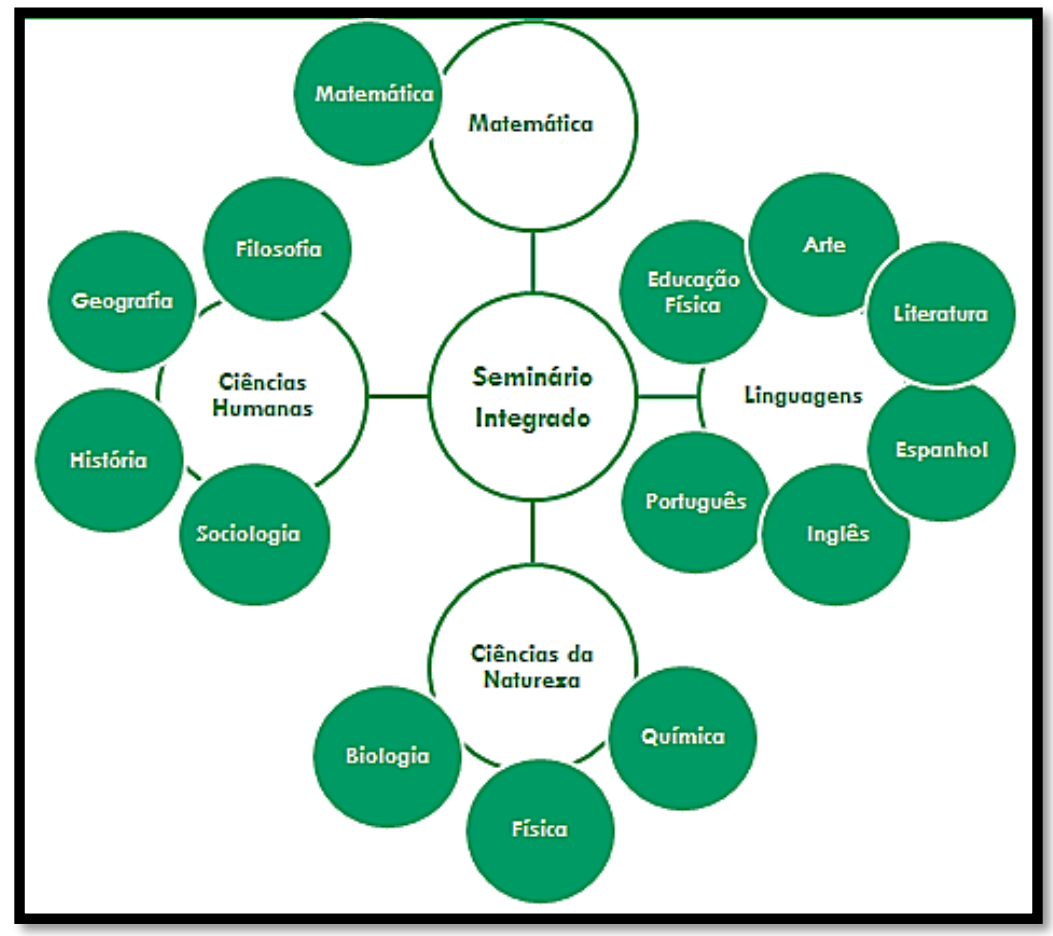

Fonte: O autor, 2015.

A imagem anterior representa, de forma concreta, como aconteceu a reestruturação curricular para que as áreas do conhecimento se encaixassem com a disciplina de Seminário Integrado (SI) á luz da qualificação dos processos de ensino e aprendizagem por meio de atividades docentes de cunho interdisciplinar. Percebe-se que as disciplinas foram agrupadas por afinidades, compondo, então, quatro grandes áreas do conhecimento: Linguagens, Humanas, Matemática e Ciências da Natureza.

Nesta visão de ampliação e maximização de saber discente e docente, por meio da reestruturação das disciplinas em áreas do conhecimento, esta proposta, em execução há três anos nas escolas gaúchas, trouxe consigo, também, concepções de formação sólida diversificada, mudanças na metodologia docente, atividades vinculadas à vida e ao trabalho e, dentre outras ações, a disciplina Seminário Integrado ${ }^{1}$ (SI), sendo vista como espaços de integração, cooperação, solidariedade e protagonismo dos estudantes frente a projetos de aprendizagem que findam os eixos Ciência, Cultura, Tecnologia e Trabalho (SEDUCRS, 2011).

\footnotetext{
${ }^{1}$ A disciplina de Seminário Integrado, enquanto conteúdo e forma de apropriação da realidade e construção da aprendizagem é um eixo articulador e problematizador do currículo. Esse Seminário se organiza a partir da elaboração de projetos nos quais a pesquisa se articula com eixos temáticos transversais, vinculados aos projetos de vida dos alunos. No transcurso do trabalho, professores e alunos organizam leituras e desenvolvem caminhos metodológicos de intervenção, possibilitando o diálogo entre os componentes curriculares pelos movimentos que encaminha (SEDUCRS, 2011, p. 22).
} 
V,13,n.1: 2017

Neste sentido, a disciplina de SI visa o desenvolvimento de atividades de cunho interdisciplinar na conexão entre as áreas do conhecimento, favorecendo a relação entre o corpo docente, os estudantes e a escola. A articulação dos eixos da politecnia, supracitados, por meio de atividades/processos construídos na disciplina SI, auxilia a formação docente em uma perspectiva interdisciplinar de docência colaborativa, uma vez que a interlocução entre os atores emerge na relação entre as áreas de conhecimento e os eixos transversais (PCN, 2000), proporcionando apropriação e possibilidades do mundo, repercutindo na construção da cidadania, na instigação da curiosidade e na transformação social que se concretiza nos meios econômico, cultural e ambiental.

Ainda, tem-se que esta reestruturação proporciona a minimização de problemas educacionais, tais como: reprovação e evasão, dicotomia entre teoria e prática e, dentre outros, participação e qualificação no ensino. Assim, Santomé (1998), afirma que:

\begin{abstract}
A educação de cidadãos e cidadãs passa, entre outras medidas, por fazer todos os esforços possíveis para evitar essa brusca ruptura entre as formas de trabalho, e por eliminar as barreiras existentes. [...] Preparar as novas gerações para conviver, partilhar e cooperar no seio das sociedades democráticas e solidárias, obriga a planejar e desenvolver propostas curriculares que contribuam para reforçar esse modelo de sociedades. Isto implica em converter as salas de aula em espaços nos quais os conteúdos culturais, habilidades, procedimentos e valores imprescindíveis para construir e aperfeiçoar esses modelos sociais são submetidos à análise e reflexão sistemática, e são praticados (p. 7).
\end{abstract}

Poder-se-ia, em uma visão ampla de reestruturação, definir esta proposta com a colocação de Santomé (1998) quando assegura que:

O currículo globalizado e interdisciplinar converte-se assim em uma categoria 'guarda-chuva' capaz de agrupar uma ampla variedade de práticas educacionais desenvolvidas nas salas de aula, e é um exemplo significativo do interesse em analisar a forma mais adequada de contribuir para melhorar os processos de ensino e aprendizagem (p. 27).

Nesta perspectiva, o presenta trabalho tem por objetivo apresentar resultados de uma pesquisa que buscou investigar e refletir sobre a maneira que a disciplina de Seminário Integrado, dentro de suas limitações e complexidades, vem proporcionando, por meio de metodologias docentes de cunho interdisciplinar, subsídios para uma formação docente colaborativa em prol da construção sociocultural e psico-cognitiva do discente. Destarte, ressalva-se que esta disciplina é um espaço-tempo presente na organização curricular do EMP, 
V,13,n.1: 2017

o qual tem por intuito garantir espaços à reflexão interdisciplinar e, sobretudo, temáticas escolhidas a partir do diálogo docente-discente; propostas de acordo com os interesses de pesquisa e estudo a serem desenvolvidos por alunos e professores.

Neste viés, privilegia-se o diálogo e a investigação de temas e conteúdos importantes e relevantes aos estudantes, proporcionando-lhes a complexidade de seus saberes com vistas à produção de aprendizagens significativas e duradouras para a própria formação crítica e social. Ainda, sabe-se que tal atividade desempenha papel fundamental na formação colaborativa do educador, pois abre possibilidades para que o mesmo atue como orientador das diversas atividades, exigindo, além de competências e habilidades, sintonia com os campos de conhecimento e os desafios da vida real.

\section{APORTES TEÓRICOS SOBRE O TEMA}

Reforçando as questões interdisciplinares nas atividades desenvolvidas na disciplina de SI para fomentar a construção de práticas pedagógicas e metodologias docentes de cunho colaborativo, percebe-se que a disciplina tem, como pano de fundo, uma proposta de promover uma forma diferente de trabalhar o conhecimento, na qual haja interação entre sujeitos-escola-conhecimentos na relação professor-aluno, professor-professor e aluno-aluno, de maneira em que o trabalho escolar torna-se dinâmico e vivo e os conteúdos científicos são problematizados e vislumbrados juntamente com as outras disciplinas.

Nesta teia, a interdisciplinaridade, proporcionada pelos trabalhos desenvolvidos de forma colaborativa na disciplina de SI, é o elo entre os profissionais do ensino, como forma de reciprocidade, de reflexão mútua, em substituição à concepção fragmentária do conhecimento, faz com que estes agentes do ensino tenham uma atitude diferenciada perante os obstáculos educacionais (AZEVEDO e ANDRADE, 2007). Assim, percebe-se que a disciplina de SI adapta a interdisciplinaridade como um mecanismo que exige uma atitude de abertura e responsabilidade. Nesta perspectiva, tanto Schon (1983) como Fazenda (1993) consideram que o professor necessita desenvolver uma ação permeada de criticidade e reflexão perante o aluno, o conhecimento, a realidade e o outro, estando disposto a vivenciar a dialogicidade que, segundo Freire (1996), entrelaça as ações de saber ouvir, falar, enxergar, calar, interagir pela via da comunicação, do diálogo e da troca mútua; logo, uma ação de colaboratividade e cooperatividade. 
V,13,n.1: 2017

Neste sentido, a interdisciplinaridade, como viés de formação colaborativa, resgata a importância do "outro", sem o qual não pode haver a troca mútua da evolução do pensamento e da linguagem, e amplia os horizontes dentro do processo sócio-histórico educacional, desempenhando a importância do conhecimento das potencialidades, dos limites, das diferenças e do processo criativo de cada ciência (AZEVEDO e ANDRADE, 2007). Portanto, há uma transformação de pensamento lógico formal em um pensamento não-linear, configurado como dialético, porque não pressupõe a conglobação de diferentes saberes, mas a construção incessante de relações entre si.

Imagem 2: Organização Curricular e Seminário Integrado

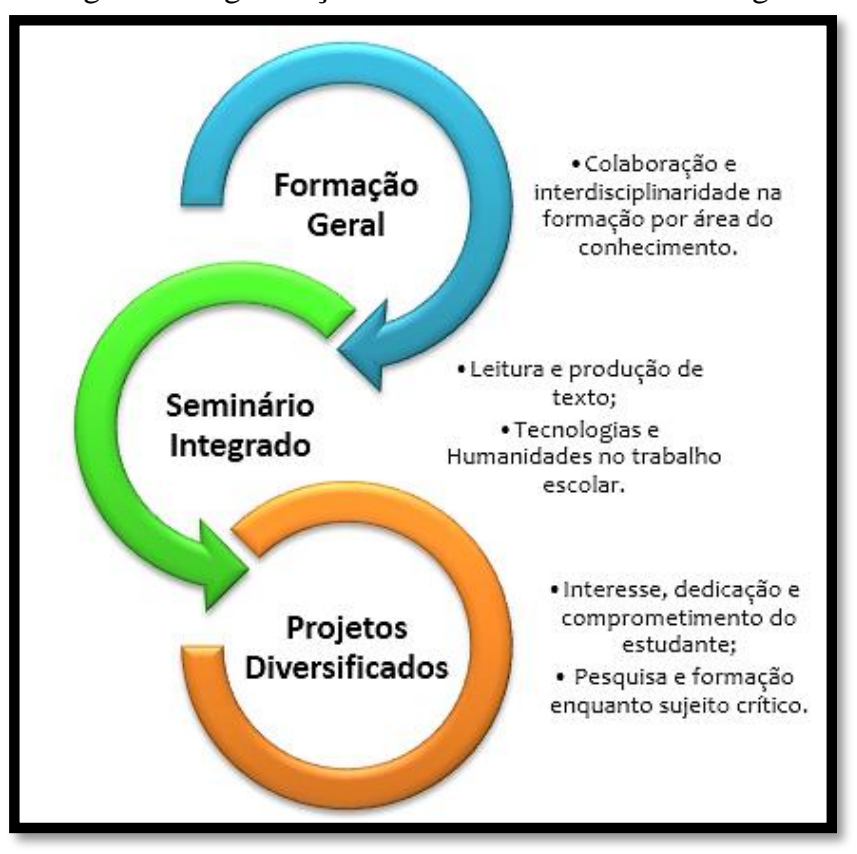

Fonte: O autor, 2015.

$\mathrm{Na}$ imagem 2, acima representada, pode-se entender a ideia principal da reestruturação curricular e a inserção da disciplina SI, a fim do desenvolvimento psicocognitivo e sociocultural do estudante por meio de atividades interdisciplinares na formação docente colaborativa. Neste desenho, pode-se predizer que a articulação destes eixos, por meio de atividades construídas na disciplina supracitada, auxilia a formação docente em uma perspectiva interdisciplinar de docência colaborativa, uma vez que a interlocução entre os atores emerge na relação entre as áreas de conhecimento e os eixos transversais (PCN, 2000), proporcionando apropriação e possibilidades do mundo do trabalho, repercutindo na construção da cidadania, na instigação da curiosidade e na transformação social que se concretiza nos meios econômico, cultural e ambiental. 
V,13,n.1: 2017

Neste desenho, tem-se que a disciplina SI privilegia o diálogo e a investigação de temas e conteúdos importantes e relevantes aos estudantes, proporcionando-lhes a complexidade de seus saberes com vistas à produção de aprendizagens significativas e duradouras para a própria formação crítica e social. Sendo assim, é pertinente pensar que na disciplina de SI o educando desenvolve, com o auxílio do colega e do professor, atividades em forma de projetos que são enriquecedores e proeminentes para o mesmo, uma vez que partem de sua vivência, contexto, desabrochando-se no viés dos saberes científicos. Isto é, a implementação de uma disciplina que desenvolve a criticidade no educando e a formação colaborativa e interdisciplinar no professor é formidável na medida em que organiza a oferta de componentes curriculares articulados em áreas de conhecimento, pois se desenvolvem espaços de multiplicação e promoção de práticas inter-relativas (professor-estudante-professor) que se tornam a centralidade do trabalho docente e da construção da aprendizagem.

Quanto a essa inovação curricular e metodológica, as Diretrizes Curriculares Nacionais - DCN - explicam que

a interdisciplinaridade é, portanto, uma abordagem que facilita o exercício da transversalidade, constituindo-se em caminhos facilitadores da integração do processo formativo dos estudantes, pois ainda permite a sua participação na escolha dos temas prioritários (DCN, 2013, p. 184).

É válido, todavia, lembrar que

os PCNEM não podem ser vistos como uma proposta pedagógica fechada e padronizada, a ser simplesmente aplicada nas escolas, mas, enquanto parâmetros ou referências, precisam ser objeto de necessários processos de discussão e ressignificação em âmbitos diversificados do meio educacional (BRASIL, 2006, p. 214).

Desta forma, acredita-se que a docência colaborativa que surge na preparação das atividades interdisciplinares acolita, também, para uma formação continuada que subsidia reflexões, razões e opções de atividades na disciplina, isto é, um trabalho reinventado e configurado na interdisciplinaridade e na colaboração docente que rompe com a padronização e homogeneidade da escola, uma vez que retrata a importância do conhecimento na ação, da reflexão na ação e da reflexão sobre a ação permeando as situações educativas (SCHON, 1983).

\section{REFERENCIAL METODOLÓGICO}


V,13,n.1: 2017

Buscando entender e refletir de que forma a disciplina de SI pode, de certa maneira, interferir sobre a formação colaborativa do professor e a sua metodologia interdisciplinar, em uma perspectiva exploratória, para apresentar como trabalhos de dada disciplina surgem no viés interdisciplinar de docência colaborativa, a pesquisa aqui destacada é de cunho etnográfico via utilização da observação em um grupo focal à qualificação dos dados.

A pesquisa etnográfica, segundo André (2004, p. 41), permite ao investigador chegar mais perto possível da escola para, posteriormente, "entender como os mecanismos $\mathrm{da} /$ na mesma operam veiculados e reelaborados no conhecimento, na atitude, na crença e nos modos de ver e de sentir a realidade e o mundo". Este fato é cabível uma vez que, interagindo com o lócus da pesquisa, é possível formular hipóteses, investigar o problema e alcançar o objetivo, já que a escola não possui uma realidade estática. Assim,

\begin{abstract}
conhecer a escola mais de perto significa colocar uma lente de aumento na dinâmica das relações e interrelações que constituem o seu dia-a-dia, apreendendo as forças que a impulsionam ou que a retêm, identificando as estruturas de poder e os modos de organização do trabalho escolar e compreendendo o papel e a atuação de cada sujeito nesse complexo interacional onde ações relações, conteúdos, são construídos, negados, reconstruídos ou modificados (ANDRÉ, 2004, p. 41).
\end{abstract}

Segundo André (2004), realizar a pesquisa e a análise de dados no viés etnográfico, na qual o pesquisador interage com o grupo, é o que permite delinear a percepção dos sujeitos, enfatizando a colaboratividade na formação docente e a dialogicidade entre teoria e prática, uma vez que a "pesquisa etnográfica busca a formulação de hipóteses, conceitos, abstrações, teorias e não sua testagem" (p. 30).

Este trabalho realizado com o grupo focal mostrou-se instigante na medida em que o grupo evidenciava dinamicidade e interatividade, uma vez que são grupos de discussão que refletem, ao receberem estímulos apropriados para o debate, sobre temas em particular, tornando-se relevantes por apresentar atividades e/ou características próprias, principalmente pelo processo de interação grupal, que é uma resultante da procura de dados (DEBUS, 1997).

Cabe enfatizar que a técnica selecionada permitiu ao pesquisador não só examinar as diferentes análises das pessoas em relação a um tema, mas, também, explorar como os fatos são articulados, censurados, confrontados e alterados por meio da interação grupal (KITZINGER, 1999). Este processo foi pertinente e conexo à atividade, pois estipulou aos 
V,13,n.1: 2017

participantes trocas, descobertas e informações ricas metodologicamente; um relacionamento recíproco na construção de atividades de forma colaborativa e construtiva.

\section{RESULTADOS E DISCUSSÕES}

A atividade desenvolvida, como protótipo de formação docente colaborativa no viés da interdisciplinaridade, nasceu nas turmas 301 e 302 de uma escola pública no norte do estado gaúcho, no ano de 2015. Esta atividade, desenvolvida na disciplina de SI, teve o intuito de proporcionar aos estudantes momentos de pesquisa e expansão de conhecimentos na relação com o outro. Em outras palavras, os estudantes desenvolveram projetos de pesquisa de interesse próprio, uma vez que estes projetos se ramificavam ao tema norteador da escola: Qualidade de $\mathrm{Vida}^{2}$, dentro da disciplina SI, orientados e direcionados pelo professor da mesma. Neste vínculo, os demais professores, responsáveis por diferentes disciplinas dentro de áreas do conhecimento, durante as aulas, buscavam estabelecer relações com os projetos desenvolvidos pelos estudantes na disciplina de SI.

Contudo, ressalva-se que, para os estudantes dos $3^{\circ}$ anos do EMP, foi proposto uma bifurcação do tema gerador da escola, abrangendo, para estes que são formandos, o viés das profissões a fim de que os mesmos pudessem se familiarizar e expandir saberes em relação a futura profissão. Ainda, o professor da determinada disciplina sujerio aos estudantes o desenvolvimento de um artigo científico que contemplasse uma pesquisa do tipo: Estado da Arte, para que pudessem, em um curto período tempo, estabelecer ligações com a própria profissão.

Referente aos temas abordados para o desenvolvimento dos projetos na disciplina de SI para a interlocução das áreas do conhecimento à luz da interdisciplinaridade e da formação docente colaborativa, tem-se a imagem 3 que apresenta, por meio de um diagrama, as profissões selecionadas para o desenvolvimento dos trabalhos.

Imagem 3: Temas elencados para o desenvolvimento dos projetos na disciplina SI.

\footnotetext{
${ }^{2} \mathrm{O}$ tema Qualidade de Vida adveio de uma pesquisa sócio-antropológica realizada no início do ano de 2013. Foi distribuído aos estudantes da escola um questionário para que, juntos de seus pais, pudessem responder de acordo com suas culturas, vivências e realidades. No termino do questionário, os professores se reuniram, realizaram uma análise qualitativa sobre o mesmo e perceberem que um tema local, abrangendo todas as singularidades e particularidades da comunidade, para ser trabalhado em sala de aula seria Qualidade de Vida.
} 


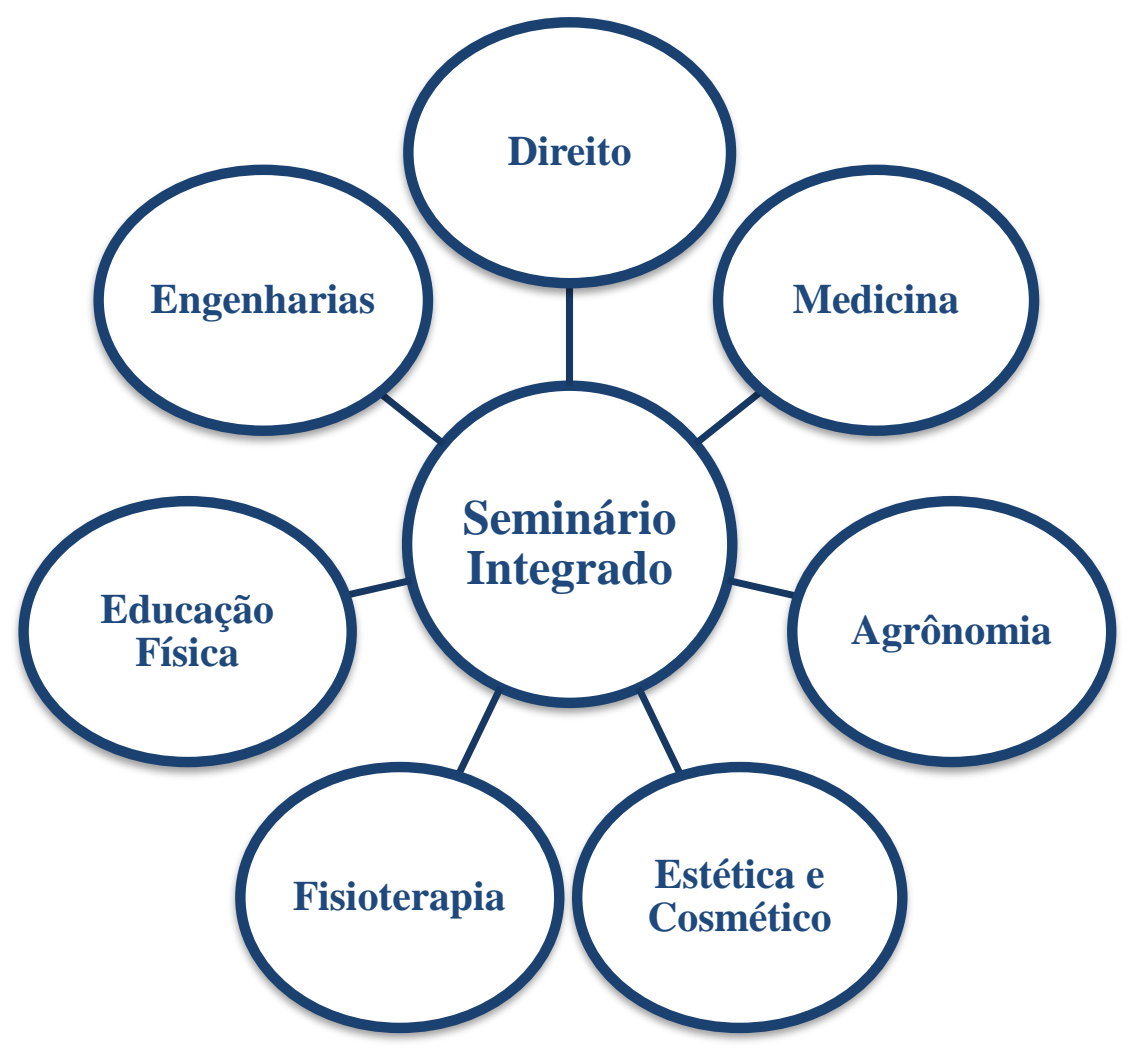

Fonte: O autor, 2015.

Na relação destes temas com a disciplina de SI e, em especial, as demais disciplinas como mecanismo interdiscipliar, inúmeras sugestões de trabalhos surgiram ao longo do período, mas apenas algumas foram concretizadas. Há critério de curiosidade e como vínculo exemplificativo, os professores da área de Linguagens desenvolveram, junto aos estudantes que investigavam a profissão Direito, uma simulação de juri; a área de Matemática plotou-se às Engenharias, buscando a validação dos cálculos básicos do currículo de uma universidade; Ciências da Natureza, por intermédio da química e da biologia, desenvolveu estudos de campo com Estética e Cosmética, analisando os produtos orgânicos de salões de beleza da cidade e, em relação à Agronomia, as questões da poluição e prejuízos causados ao meio ambiente por meio de agrotóxicos. Ainda, trabalhou-se Fisioterapia e Educação Física na Associação de Pais e Amigos dos Excepcionais (APAE), com o auxílio dos professores da área de Humanas.

Assim, nota-se a emersão da interdisciplinaridade e a formação docente colaborativa por meio da disciplina SI, uma vez que ao realizar trabalhos que necessitam diálogos e discussões entre diferentes professores há, também, troca de saberes e experiências, favorecendo o desenvolvimento de ações, objetivos e propósitos em comum. Afinal, como relatam John-Steiner, Weber e Minnis (1998, p. 774), o foco exclusivo no diálogo acaba por mitigar a "complementaridade de habilidades, esforços e papéis nas relações de confiança como 
V,13,n.1: 2017

alternativa para a falta de equidade e para o poder desigual em algumas colaborações ou para todos fazendo trabalhos idênticos".

O professor, na perspectiva da interdisciplinaridade, não é um mero repassador de conhecimentos, mas é reconstrutor juntamente com seus alunos; o professor é, conseqüentemente, um pesquisador que possibilita aos alunos, também, a prática da pesquisa. A problematização como metodologia para a reconstrução de construtos dá condições ao aluno de mover-se no âmbito das teorias, das diferentes áreas do saber, construindo a teia de relações que vai torná-lo autônomo diante da autoridade do saber. $\mathrm{O}$ professor pesquisador constitui-se, portanto, em agente necessário de uma formação calçada na interdisciplinaridade (TOMAZETTI, 1998, p. 13).

Neste viés, tem-se que a interdisciplinaridade é a ligação que possibilita o estabelecimento de inúmeras relações das disciplinas com o contexto em num processo recíproco de aprendizagens múltiplas e intermináveis. Os professores e os estudantes passam a estabelecer diferentes interconexões entre a epistemologia dos conhecimentos e o mundo que os cerca, a fim de exercitar cotidianamente seus saberes e as relações entre teoria e prática; logo, tem-se uma ação colaborativa entre os pares e uma

atividade conjunta na qual participantes se engajam mutualmente na definição e desenvolvimento de objetivos no interior da própria atividade, resolvendo problemas, coordenando esforços, respeitando-se mutuamente como os mais valiosos agentes de suas próprias ações e tentando integrar suas atividades com outros aspectos de suas vidas (MATUSOV; WHITE, 1996, p. 11).

Na mesma direção, Roth e Tobin $(2001 ; 2002 ; 2004)$ exploram esta atividade de ensino e aprendizagem entre professores e alunos como prática que "permite a emersão de desafios mais significativos e, deste modo, abre possibilidades para se aprender com o outro não somente de modo explícito, mas igualmente e ainda mais importante, de modo tácito" (ROTH; TOBIN, 2002, p. 121). Por sua natureza e formas de organização, o ensino colaborativo potencialmente produz as bases comuns a partir das quais participantes da ação refletem sobre os eventos em sessões de diálogo cogerativo, cujo propósito é promover aprendizagem por meio de oportunidades de analisar questões significativas sob os diversos pontos de vista dos envolvidos no mesmo evento (MATEUS, 2013). Nesta linha, Clark et al. (1996) corroboram, pois, como foco em pesquisas colaborativas, definem colaboração como diálogo e como "partilha e mutualidade não em termos de fazer o mesmo trabalho de pesquisa, mas, ao contrário, em termos de compreender o trabalho uns dos outros" (CLARK et al., 1996, p. 196). 
V,13,n.1: 2017

Nesta perspectiva, epistemologicamente, percebe-se que a disciplina de SI como conjunto de disciplinas em aspecto legalista potencializa as possibilidades de que diferentes conhecimentos sejam rearticulados tanto a partir daquilo que está consolidado como conhecimento historicamente acumulado quanto a partir daquilo que se vivencia no contexto dos diferentes estudantes.

Pedagogicamente, a disciplina potencializa as possibilidades de que diferentes formas de organização curricular superem as dificuldades presentes na estrutura das áreas do conhecimento e das escolas públicas gaúchas de educação básica, pois a proposta para o currículo integrado desta modalidade de ensino tem em sua concepção a base na dimensão politécnica, constituindo-se no aprofundamento da articulação das áreas de conhecimentos e suas tecnologias na perspectiva de que a apropriação e a construção de conhecimento embasam e promovem a inserção social da cidadania, considerando aspectos epistemológicos, sócioantropológicos, sociopedagógicos e filosóficos (SEDUCRS, 2011).

Assim, a formação docente, neste espaço potencial de transição entre teoria e prática, fazer e dizer pedagógico, passa a constituir-se de forma colaborativa; uma forma de potencializar e enriquecer a maneira de o professor pensar, agir e resolver problemas, criando possibilidades de sucesso à difícil tarefa pedagógica. Ainda, tem-se benefícios entre estudantes; os trabalhos de Coll Salvador (1994) e Colaço (2004) são exemplos dos que realizam uma análise ampla dos efeitos desse tipo de atividade entre estudantes. Esses autores apontam ganhos em termos de: 1) socialização (o que inclui aprendizagem de modalidades comunicacionais e de convivência), controle dos impulsos agressivos, adaptação às normas estabelecidas (incluindo a aprendizagem relativa ao desempenho de papéis sociais) e superação do egocentrismo (por meio da relativização progressiva do ponto de vista próprio); 2) aquisição de aptidões e habilidades (incluindo melhoras no rendimento escolar); e 3) aumento do nível de aspiração escolar.

Neste sentido, a caracterização sobre a politecnia como dada por Azevedo (2012) e as atividades desenvolvidas de forma colaborativa, veem contribuindo para que a disciplina que inter-relaciona as diferentes áreas do conhecimento seja percebida e afirmada como um espaço dinamizador, o qual tem por intuito receber e decodificar a diversidade contida nas diferentes áreas do conhecimento, impulsionando estudantes e professores a entrarem em oscilação pela/na busca de respostas e formulações de novos questionamentos a partir dos diferentes contextos sociais e produtivos que cercam os diferentes trabalhos desenvolvidos na disciplina. 
V,13,n.1: 2017

Assim, rompe-se com a homogeneidade da sala de aula, tornando as atividades docentes colaborativas e construtivas, uma vez que o SI, constituindo-se nesse espaço articulador, viabiliza inúmeras formas de questionar e problematizar a realidade, tendo como pressuposto garantir que o movimento de saberes entre professores e alunos ocorra de forma intencional e constante.

Dentro desta reforma curricular, regida pelos pressupostos sintetizados até aqui, estão colocados seis alicerces que a sustentam: a relação parte-totalidade - com vistas a compreender a realidade como um todo; o reconhecimento de saberes - docentes e discentes, em permanente diálogo; a teoria-prática - uma demanda antiga de aproximação do ensino com a realidade; a interdisciplinaridade - principal aspecto abordado neste trabalho e que está em consonância e, quiçá, propulsiona todos os outros aspectos; a avaliação emancipatória; e, a pesquisa - item fundamental para a politecnia e trabalho como princípio educativo (SEDUCRS, 2011, pp. 17-21). A partir destes fundamentos, os sujeitos são instigados a pesquisar e compreender o mundo em que vivem, relacionar teoria e prática, ir e vir, criticar, construir e forjar elementos que favoreçam o desenvolvimento social e cultural de todos os envolvidos.

\section{CONSIDERAÇÕES FINAIS}

A reestruturação do Ensino Médio trouxe na organização curricular o SI, disciplina trabalhada no turno inverso, que se constitui no espaço de articulação entre todas as disciplinas, sendo, segundo Azevedo (2012), o "estuário"3, isto é, mecanismo onde deve-se adequar os componentes curriculares que contribuem para a problematização e fundamentação dos fenômenos investigados a partir de projetos de pesquisa. Neste desenho, por meio da investigação sobre o trabalho desenvolvido, pode-se perceber que a disciplina, advinda com a implementação do EMP nas escolas gaúchas, tem possibilitado o diálogo entre os componentes curriculares, seja pela consideração de apenas um único objetivo ou pela expansão contextualizada dos componentes entre si.

Do mesmo modo, tem proporcionado múltiplas maneiras aos estudantes para difundirem as informações obtidas através de pesquisas mediadas pelos professores, assim como articulação entre o tempo e o espaço para o planejamento e o envolvimento dos sujeitos

\footnotetext{
${ }^{3} \mathrm{O}$ termo estuário incidiu de uma palestra intitulada: Implementação do Seminário Integrado no Ensino Médio Politécnico, proferida pelo professor Dr. Jose Clovis Azevedo. Porto Alegre: Café, Sala Paulo Freire, 26 de dezembro de 2012.
} 
V,13,n.1: 2017

na execução e acompanhamento de projetos de vida a serem efetivados no viés dos eixos: ciências, tecnologia, cultura e trabalho, tecendo uma rede de conhecimentos que identifica e cria possibilidades de intervenção na realidade, seja pela construção da aprendizagem e da aplicação dos conhecimentos construídos ou pela materialização do processo de ensino e da aprendizagem contextualizada e interdisciplinar. Portanto, “constitui-se, também, em espaços de comunicação, socialização, planejamento e avaliação das vivências e práticas pedagógicas na disciplina" (SEDUCRS, 2011, p. 195).

Destarte, a interdisciplinaridade, assim como a dialogicidade e a colaboratividade, tem ganhado espaço na perspectiva de formação docente e discente, pois a realidade das escolas públicas tem desmistificado as ideias de mesmice e tradicionalismo nos afazeres docente, caracterizada como:

a concepção de ensino-aprendizagem correspondente ao modelo transmissãorecepção é retratada na prática de ensino encaminhada quase que exclusivamente para a retenção do que se considera "saber sistematizado", de posse do professor, transmitido ao aluno, considerado, por sua vez, como "tábula rasa"” (PCNEM, 2006, p.208).

A averiguação das observações sobre o público-alvo na disciplina de SI mostrou que os trabalhos nesta disciplina ocorrem de forma interdisciplinar à luz da docência colaborativa, pois os professores integram os segmentos escolares em um só objetivo. Pode-se, também, perceber que as atividades desenvolvidas nos trabalhos ao longo do ano letivo necessitam, além de competências e habilidades por parte dos professores, uma formação colaborativa e inter-relacionada, pois corroboram na análise textual e interpretativa dos saberes científicos sobre temáticas estudadas, assim como em momentos essenciais na relação com as atividades científicas, na utilização de recursos audiovisuais e na postura em prol da exposição reflexiva sobre a conclusão das atividades.

Desta forma, os professores desenvolvem atividades relacionadas à construção crítica do estudante, pois ampliam saberes no viés de textos e atividades básicas, proporcionando condições para uma análise rigorosa e mais radical dos mesmos; interpretação de conteúdo; discussão de problemas presentes explícita ou implicitamente nas atividades; explicações múltiplas em sala de aula; iniciação e estimulação à pesquisa científica, excitando as energias e possibilidades latentes nos alunos; e, dentre outras atividades, auxiliando os alunos no desenvolvimento de trabalhos pessoais, originais e de ampla pesquisa científica, 
V,13,n.1: 2017

familiarizando-os com o uso e manejo de manuscritos, textos e documentos, isto é, pesquisa de alta qualidade.

Assim sendo, Vygotsky (2007) coloca o professor como mediador da construção da consciência do educando na perspectiva sociocultural. Utilizando instrumentos de ensino para mobilizar os signos internos dos alunos e, também, por meio dos seus próprios signos o educador pode enriquecer sua prática pedagógica e garantir uma aprendizagem que permita ao aluno crescer tanto no âmbito do desenvolvimento cognitivo, quanto na interação com o outro. Assim, nota-se o surgimento de uma abordagem diferenciada para os processos educativos; momento em que o educador maneja instrumentos e signos para que estes sejam compartilhados pelos estudantes. Essa atividade mediada recíprocamente tem se tornado realidade nas escolas gaúchas no viés da docência colaborativa que se estabelece no Ensino Médio Politécnico.

Destarte, a disciplina SI, enquanto espaço de construção de saberes e formação colaborativa docente, instiga professor e estudante à apropriação da realidade e à construção da aprendizagem, pois articula vínculos entre problemas e soluções. Igualmente, foi possível analisar que a disciplina tem se tornado, cada vez mais, um momento de articulação entre conhecimento científico e conhecimento social, constituindo-se, por natureza, no exercício da interdisciplinaridade e na formação colaborativa dos docentes.

Em suma, a elaboração das atividades na disciplina está voltada a estratégias diversas no sentido de fomentar o trabalho em grupo, o diálogo com o outro, a interatividade e a construção de uma docência coletiva. Na teia interdisciplinar, privilegiaram-se momentos de aprendizagem que corroboraram na distinção progressiva, na reconciliação integradora (AUSUBEL, 1978) e na interação social (VYGOTSKY, 2007), a fim de desenvolver atividades (leitura e discussão de textos, realização de atividades experimentais e visitas orientadas) de forma ativa e reflexiva no que tange à complexidade dos conteúdos relacionados à ciência, tecnologia, trabalho e cultura. 
V,13,n.1: 2017

\section{REFERÊNCIAS BIBLIOGRÁFICAS}

ANDRÉ, M. Etnografia da prática escolar. 11. ed.. São Paulo: Papirus, 2004.

AUSUBEL, D. P. Psicologia educativa: un punto de vista cognoscitivo. México: Trillas, 1978.

AZEVEDO, Maria Antonia Ramos de.; ANDRADE, Maria de Fátima Ramos de. O conhecimento em sala de aula: a organização do ensino numa perspectiva interdisciplinar. Educar em Revista, Curitiba, n. 30, p. 235-250, 2007. Editora UFPR.

BRASIL. Ministério da Educação e Cultura. Secretaria de Educação do Ensino Médio. Parâmetros Curriculares Nacionais: Bases Legais. Brasília, 2000.

Ministério da Educação e Cultura. Secretaria de Educação do Ensino Médio.

Parâmetros Curriculares Nacionais. Ciências da natureza, matemática e suas tecnologias / Secretaria de Educação Básica. - Brasília: Ministério da Educação, Secretaria de Educação Básica, 2006.135 p.

Ministério da Educação e Cultura. Secretaria de Educação Básica. Parâmetros

Curriculares Nacionais para o Ensino Médio - Brasília: Ministério da Educação, Secretaria de Educação Básica, 2006.

2013.

Diretrizes Curriculares Nacionais para o Ensino Médio. Brasília: MEC/Semtec,

CLARK, C. et al. Collaboration as Dialogue: Teachers and Researchers Engaged in Conversation and Professional Development. American Educational Research Journal, v. 3, n. 1, p. 193-231, 1996.

COLAÇO, V. de F. R. Processos interacionais e a construção de conhecimento e subjetividade de crianças. Psicologia: Reflexão e Crítica, Porto Alegre, v. 17, n. 3, p. 333340, 2004.

COLL SALVADOR, C. Aprendizagem escolar e construção do conhecimento. Porto Alegre: Artes Médicas, 1994.

DEBUS, M. Manual para excelência en La investigación. Mediante grupos focales. Washington (USA): Academy for Educational Development; 1997.

FAZENDA, I. C. A. Práticas interdisciplinares na escola. 2. ed. São Paulo: Cortez, 1993.

FREIRE, P. Pedagogia da autonomia: saberes necessários à prática educativa. São Paulo: Paz e Terra, 1996.

JOHN-STEINER, V.; WEBER, R. J.; MINNIS, M. The Challenge of Studying Collaboration. American Educational Research Journal, v. 35, p. 773-783, 1998.

KITZINGER, J. Introduction: the challenge and promise of focus groups. In: Kitzinger, J. Developing focus group research: politics, theory and practice. London (UK): Sage, 1999. p.1-20. 
V,13,n.1: 2017

MATEUS, E. Práticas de formação colaborativa de professores/as de inglês: representações de uma experiência no Pibid. Rev. bras. linguist. apl. [online]. 2013, vol.13, n.4, pp. $1107-$ 1130.

MATUSOV, E.; WHITE, C. Defining the Concept of Open Collaboration from a Sociocultural Framework. Cognitive Studies: The Bulletin of the Japanese Cognitive. Science Society, v. 3, n. 4, p. 10-13, 1996.

ROTH, W. M.; TOBIN, K. Coteaching: From Praxis to Theory. Teachers and Teaching: Theory and Practice, v. 10, n. 2, p. 161-180, Apr. 2004.

W. M.; TOBIN, K. Redesigning an "Urban" Teacher Education Program: An Activity

Theory Perspective. Mind, Culture and Activity, v. 9, n. 2, p. 108-131, 2002.

W. M.; TOBIN, K. The Implications of Coteaching/Cogenerative Dialogue for Teacher Evaluation: Learning from Multiple Perspectives of Everyday Practice. Journal of Personnel Evaluation in Education, v. 15, n. 1, p. 7-29, 2001.

SANTOMÉ, J. Globalização e Interdisciplinaridade: o currículo integrado. Porto Alegre: Artes Médicas, 1998.

SCHON, D. The reflective practitioner: how professionals think in action. San Francisco: Jossey-Bass, 1983.

SECRETARIA DO ESTADO DO RIO GRANDE DO SUL. Proposta pedagógica para o Ensino Médio Politécnico e Educação Profissional integrada ao Ensino Médio. Porto Alegre. 2011. Disponível em: http://www.educacao.rs.gov.br/dados/ens_med_proposta.pdf. Acesso em 10 set. 2015.

TOMAZETTI, E. Estrutura conceitual para uma abordagem do significado da interdisciplinaridade: um estudo crítico. UFSM, n. 10, p. 1-43, 1998.

VYGOTSKY, L. S. A formação social da mente. 7. ed. São Paulo: Martins Fontes, 2007 